\title{
Exposure to epichlorohydrin and dimethylformamide, glutathione S-transferases and sister chromatid exchange frequencies in peripheral lymphocytes
}

Received: 24 November 1998 / Accepted: 9 March 1999

\begin{abstract}
Workers in epoxy resin, synthetic leather, and printed circuit board manufacturing plants are exposed to epichlorohydrin (ECH), or dimethylformamide (DMF), or both. ECH, an alkylating agent, has been shown to cause malignancy in animals, but its genotoxicity in humans is unclear. DMF is a well-known hepatotoxic chemical, although evidence of its genotoxicity in humans is also limited. In this study, we examined the effects of exposure to ECH and DMF on sister chromatid exchange (SCE) in plant workers, in order to examine the genotoxicity of these two agents. Because the genotoxicity of certain agents can be modulated by metabolic traits, we also investigated influence of the glutathione S-transferase (GST) $\mu$ (GST M1) and GST $\theta$ (GST T1) genes on the genotoxicity of ECH and DMF. A total of 85 male plant workers were included in this study. The subjects were divided into five exposure groups, based on their job titles and the airborne $\mathrm{ECH}$ and DMF concentrations in their areas of work. A questionnaire was administered to obtain detailed occupational, smoking, alcohol consumption, and medication histories. Standardized cytogenetic methods were used to determine the frequency of sister chromatid exchange (SCE) in peripheral blood lymphocytes. GST M1 and GST T1 genotypes were identified using polymerase
\end{abstract}

T-J. Cheng $(\bowtie) \cdot$ S-J. Hwang

Graduate Institute of Occupational Medicine and Industrial Hygiene, College of Public Health, National Taiwan University, Taipei, Taiwan, R.O.C.

e-mail: tcheng@ha.mc.ntu.edu.tw

Tel.: + 886-2-23957845; Fax: + 886-2-23959845

T-J. Cheng

Center for the Research of Environmental and Occupational Diseases, College of Public Health, National Taiwan University, Taipei, Taiwan, R.O.C.

H-W. Kuo

Graduate Institute of Environmental Health,

China Medical College, Taichung, Taiwan, R.O.C.

J-C. Luo - M.J.W. Chang

College of Medicine, Chang Gung University,

Taoyuan, Taiwan, R.O.C. chain reaction (PCR). In analysis, smoking was significantly associated with increased SCE frequency $(P<0.01)$. Workers with high ECH exposure also had significantly higher SCE frequencies than those with low or no ECH exposure $(P<0.05)$. However, DMF exposure was not associated with SCE frequency. The GST M1 null genotype was also found to be associated with an increased SCE frequency $(P=0.06)$. We conclude that ECH exposure may be associated with genetic toxicity and that DMF does not appear to be genotoxic.

Key words Sister chromatid exchange · Epichlorohydrin · Dimethylformamide · Glutathione S-transferase (GST) M1 · GST T1

\section{Introduction}

Epichlorohydrin (ECH; CAS no. 106-89-8) has been widely used in the production of epoxy resin, pesticides, and drugs. Animal studies have shown that ingestion of $\mathrm{ECH}$ induces forestomach tumors, while inhalation of ECH leads to cancer of the nasal cavity (Konishi et al. 1980; Laskin et al. 1980; Webster et al. 1985). The carcinogenicity of ECH in humans, however, has previously not been extensively studied. ECH is a direct-acting alkylating agent and is classified by the International Agency for Research on Cancer as a group 2A carcinogen (IARC 1982). Previous studies on the genotoxicity of ECH have shown increased frequencies of chromosomal aberrations in ECH-exposed workers (Sram et al. $1980,1983)$ Sister chromatid exchange (SCE) is one of the most sensitive indicators of genetic damage, particularly for alkylating agents (Wolff 1982). Elevation of SCE frequency has been demonstrated in peripheral lymphocytes treated with ECH (White 1980). However, SCE studies in workers exposed to ECH have not been reported.

In some cases, workers who are exposed to ECH are also exposed to dimethylformamide (DMF; CAS no. 6812-2), which is known to cause liver damage (Fleming 
et al. 1990; Wang et al. 1991). A comprehensive mutagenicity study including Ames' test, and induction of chromosomal aberration and SCE after in vitro exposure to DMF in human lymphocytes, and micronucleus test in DMF-treated mice showed negative results (Antoine et al. 1983). However, a recent study reported an association of DMF exposure with SCE in peripheral lymphocytes in DMF workers (Seiji et al. 1992).

Recent reports have indicated that metabolic traits might modulate the effects of various chemicals. Animal studies have shown that ECH may be conjugated with glutathione to become N-acetyl-S-(2,3-dihydroxypropyl) cysteine and $\mathrm{N}, \mathrm{N}^{\prime}$-bis-acetyl-S-S'-(1,3-biscysteinyl) propane-2-ol (De Rooij et al. 1996). Epoxides have been reported to be substrates for glutathione S-transferases (GSTs; Ketterer 1988). Recently, polymorphisms of both GST $\mu$ (GST M1) and GST $\theta$ (GST T1) have been reported (Nelson et al. 1995). Smokers with deficiency in GST M1 activity had increased SCE frequency (Van Poppel 1993). Additionally, peripheral lymphocytes with deficiency in GST T1 activity had increased SCE after treatment with 1,2-expoxy-3-butene (Bernardini et al. 1998). Thus, ECH workers with susceptible GST M1 or GST T1 may be associated with increased genetic damage. In this paper, we used SCE in peripheral lymphocytes as a marker of DNA damage to investigate the genotoxicity of ECH and DMF in exposed workers. In addition, we investigated the modulatory effects of GST M1 and GST T1 on ECH-induced SCE.

\section{Materials and methods}

\section{Study population}

Eighty-five workers were recruited from a resin synthesis plant where synthetic leather, epoxy resin, and printed circuit (PC) boards, respectively are manufactured. Area and personal sampling was performed to determine the ECH and DMF levels of these study subjects. Workers engaged in epoxy resin manufacturing were considered to have increased $\mathrm{ECH}$ exposure, workers at the synthetic leather manufacturing plant were considered to have increased DMF exposure, and PC board plant workers were considered to have both ECH and DMF exposure. Study subjects were divided into five groups on the basis of the sampling results (Table 1). The cut-off points for high and low exposure to ECH and DMF were time-weighted average (TWA) $1 \mathrm{ppm}$ and $10 \mathrm{ppm}$ respectively. Twenty-one workers engaged in maintenance, $\mathrm{ECH}$ unloading, or research and development in the epoxy resin plant had high ECH (median $2.0 \mathrm{ppm}$; range $1.1 \sim 3.9 \mathrm{ppm}$ ) and low DMF (median $2.9 \mathrm{ppm}$; range $1.1 \sim 4.2 \mathrm{ppm}$ ) exposure. Twentyone operators in the epoxy resin production plant had low ECH (median $0.2 \mathrm{ppm}$ ) and low DMF (median $2.5 \mathrm{ppm}$ ) exposure. Fourteen workers engaged in dipping of PC boards had low ECH (median $0.1 \mathrm{ppm}$ ) and high DMF exposure (median $23.5 \mathrm{ppm}$ ). Nine workers engaged in mixing, pressing, and maintenance at the PC board production plant had low DMF (median $5.2 \mathrm{ppm}$; range $0.9 \sim 5.3 \mathrm{ppm}$ ) exposure, and no ECH exposure. Twenty workers engaged in mixing and spraying at a leather synthetic plant had high DMF (median 24.8 ppm; range $11.4 \sim 83.3 \mathrm{ppm}$ ) but without $\mathrm{ECH}$ exposure.

Epidemiological data and specimen collection

Informed consent was obtained from all subjects. Questionnaires were administered to all study subjects by interviewers to obtain detailed occupational, smoking, and medical histories. Smokers were defined as those who had been smoking during 1 month before blood collection. Alcohol drinking greater than once each week was defined as habitual alcohol drinking. Peripheral venous blood was drawn into heparinized tubes and processed for SCE analysis within $24 \mathrm{~h}$.

\section{SCE assay}

The SCE frequency in peripheral lymphocytes was determined with a standard cytogenetic assay (Cheng et al. 1995). Briefly, $1 \mathrm{ml}$ of whole blood was added to $9 \mathrm{ml}$ of culture medium with phytohemagglutinin, and the mixture was maintained at $37.5^{\circ} \mathrm{C}$ in $5 \%$ $\mathrm{CO}_{2}$ for $72 \mathrm{~h}$. Fifty micromolar 5-bromodeoxyuridine was added to the culture at $24 \mathrm{~h}$ to achieve differential staining. The lymphocytes were harvested with hypotonic $\mathrm{KCl}$ solution and fixed in methanol: acetic acid $(3: 1, v / v)$. The chromosomes were stained using a modification of the fluorescence-plus Giemsa technique of Perry and Wolff (1974). For each subject, 50 metaphases were scored to determine the mean SCE frequency per cell. All slides were scored by one reader who was blind to the status of the subjects.

\section{Genotyping of GST M1 and GST T1}

GST M1 and GST T1 genotypes were determined by co-amplification of both genes (Comstock et al. 1990; Pemble et al. 1994) with polymerase chain reaction (PCR). The primers used for the GST M1 gene were 5'-CTGCCCTACTTGATTGATGGG-3' and $5^{\prime}$-CTGGATTGTAGCAGATCATGC- $3^{\prime}$. The primers used for the GST T1 gene were 5'-TTCCTTACTGGTCCTCACATCTC- $3^{\prime}$ and $5^{\prime}$-TCACCGGATCATGGCCAGCA- ${ }^{\prime}$. The human $\beta$-globin
Table 1 Median exposure concentrations of different categories of exposure and jobs in resin synthesis plants. ( $E$ Epoxy resin plant $\cdot P$ PC board production plant $\cdot S$ synthetic leather production plant $\cdot E C H$ epichlorohydrin $\cdot D M F$ dimethylformanide $\cdot N D$ not detected $\cdot T W A$ time weighted average)

\begin{tabular}{|c|c|c|c|c|}
\hline \multicolumn{2}{|c|}{ Categories of exposure } & \multirow[t]{2}{*}{ Job description } & \multicolumn{2}{|c|}{$\begin{array}{l}\text { Median TWA } \\
\text { concentrations (ppm) }\end{array}$} \\
\hline $\mathrm{ECH}$ & DMF & & $\mathrm{ECH}$ & DMF \\
\hline \multirow[t]{3}{*}{ High } & \multirow[t]{3}{*}{ Low } & Maintenance (E) & 1.1 & 2.9 \\
\hline & & ECH unloading (E) & 2.0 & 1.1 \\
\hline & & Research and development (E) & 3.9 & 4.2 \\
\hline Low & High & Dipping of $\mathrm{PC}$ board $(\mathrm{P})$ & 0.1 & 23.5 \\
\hline Low & Low & Operator $(\mathrm{E})$ & 0.2 & 2.5 \\
\hline \multirow[t]{3}{*}{ None } & \multirow[t]{3}{*}{ High } & Spraying (S) & ND & 24.8 \\
\hline & & Mixing (S) & ND & 11.4 \\
\hline & & Assembling $(\mathrm{P})$ & ND & 11.2 \\
\hline \multirow[t]{3}{*}{ None } & \multirow[t]{3}{*}{ Low } & Mixing $(\mathrm{P})$ & ND & 5.3 \\
\hline & & Pressing $(\mathrm{P})$ & ND & 5.2 \\
\hline & & Maintenance $(\mathrm{P})$ & ND & 0.9 \\
\hline
\end{tabular}


gene $(110 \mathrm{bp})$ was also amplified in each reaction as a positive control to confirm the presence of amplifiable DNA in the samples. The primers used for $\beta$-globin were $5^{\prime}$-ACACAACTGTGTTCACTAGC-3' and 5'-CAACTCATCCACGTTCACC-3'. The amplifications were carried out with denaturation at $94{ }^{\circ} \mathrm{C}$ for $1 \mathrm{~min}$ $30 \mathrm{~s}$, annealing at $52{ }^{\circ} \mathrm{C}$ for $1 \mathrm{~min}$, and extension at $65^{\circ} \mathrm{C}$ for $1 \mathrm{~min}$. The reaction products were then resolved by electrophoresis in $2 \%$ agarose gels, stained with ethidium bromide, and photographed under ultraviolet light. Individuals with one or more GST M1 alleles had a 273-bp fragment, and individuals with one or more GST T1 alleles had a 480-bp fragment.

\section{Statistical analysis}

Comparison between different exposure group for age, duration of employment, smoking, drinking, and the prevalence of genotype of GST M1 and GST T1 were made using analysis of variance (ANOVA) for continuous variables and a $\chi^{2}$-test for discrete variable. Crude SCE frequency was evaluated using stratified analysis by smoking and various factors. Student's $t$-test was used to test the association of SCE frequency with different metabolic traits, age and exposures. Subsequently, general linear model (GLM) was used to test the association between SCE frequency and the above risk factors.

\section{Results}

The basic characteristics of the study subjects are summarized in Table 2. In the five exposure groups, the smoking and GST M1 distribution were not different, whereas age, drinking, duration of employment, and GST T1 were significantly different. Of the subjects with low DMF exposure, those with high ECH exposure had $8.3 \mathrm{SCEs} / \mathrm{cell}$, those with low ECH exposure had 7.8 SCEs/cell, and those without ECH exposure had 7.4 SCEs/cell. Of the subjects with high DMF exposure, those with low ECH exposure had 7.7 SCEs/cell, and those without ECH exposure had 7.8 SCEs/cell (Fig. 1).

Smokers had a significantly higher SCE frequency than non-smokers (Table 3). When the SCE frequency was stratified by smoking, those younger than 32 years of age had higher SCE frequencies than those older than
32, although this difference was not significant. Those with longer durations of employment had lower SCE frequencies than those with shorter durations of employment, in both the smoking and non-smoking groups; again, this difference did not reach statistical significance. Of the non-smokers, workers with high ECH exposure had higher SCE frequencies than those with low or no ECH exposure, but the difference was not statistically significant. Among smokers, workers with high ECH exposure had a significantly higher SCE frequency than those with low or no ECH exposure $(P<0.02)$. Smokers with high DMF exposure did not have higher SCE frequencies than smokers with low DMF exposure. Similarly, nonsmokers with high DMF exposure did not have significantly higher SCE frequencies than nonsmokers with low DMF exposure. In both the smoking and nonsmoking groups, those with the GST M1 null genotype had higher SCE frequencies that those with at least one GST M1 allele. However, this difference was not significant. The difference in the SCE frequencies of subjects with the GST T1 null and non-null genotype was not significant.

Multiple regression analysis was performed to analyze the relationships of SCE with potential explanatory variables including age, smoking, ECH exposure, DMF exposure, and the inherited metabolic traits conferred by the GST M1 and GST T1 genes (Table 4). Smoking and ECH exposure were significantly associated with increased SCE frequencies $(P<0.01$ and 0.05 , respectively). GST M1 was also associated with increased SCE frequency $(P=0.06)$, whereas age was not. Neither the interaction of smoking and $\mathrm{ECH}$ exposure nor the association between DMF exposure and SCE frequency was significant.

\section{Discussion}

This study showed smoking and exposure to ECH are associated with an increased SCE frequency. Several

Table 2 Basic characteristics of study subjects exposed to ECH and DMF. (GST M1 Glutathione S-transferase $\mu \cdot G S T$ T1 GST $\theta$ )

\begin{tabular}{|c|c|c|c|c|c|c|}
\hline \multirow[t]{2}{*}{ Variable } & \multirow{2}{*}{$\begin{array}{l}\text { High } \mathrm{ECH}^{\mathrm{a}} \\
\text { Low DMF } \\
n=21\end{array}$} & \multicolumn{2}{|l|}{ Low ECH } & \multicolumn{2}{|l|}{ None ECH } & \multirow{2}{*}{$\begin{array}{l}\text { Total } \\
n=85\end{array}$} \\
\hline & & $\begin{array}{l}\text { High DMF } \\
n=14\end{array}$ & $\begin{array}{l}\text { Low DMF } \\
n=21\end{array}$ & $\begin{array}{l}\text { High DMF } \\
n=20\end{array}$ & $\begin{array}{l}\text { Low DMF } \\
n=9\end{array}$ & \\
\hline Age (years, mean $\pm \mathrm{SD})^{*}$ & $30.5 \pm 5.0$ & $33.6 \pm 3.9$ & $29.9 \pm 3.9$ & $34.6 \pm 6.3$ & $31.3 \pm 4.9$ & $31.9 \pm 5.2$ \\
\hline $\begin{array}{l}\text { Duration of employment* (years) } \\
\text { Smoking }^{\mathrm{b}} \text {, no. }(\%)\end{array}$ & $4.5 \pm 4.4$ & $7.0 \pm 2.9$ & $4.2 \pm 2.9$ & $9.2 \pm 5.7$ & $6.2 \pm 4.1$ & $6.1 \pm 4.5$ \\
\hline $\begin{array}{l}\text { Yes } \\
\text { Drinking } \\
\end{array}$ & $9(43)$ & $6(43)$ & $13(62)$ & $11(55)$ & $3(33)$ & $42(49)$ \\
\hline $\begin{array}{l}\text { Non-null } \\
\text { GST T1, no. }(\%)^{*}\end{array}$ & $11(52)$ & $7(50)$ & $10(48)$ & $8(40)$ & $3(33)$ & $39(46)$ \\
\hline Non-null & $7(33)$ & $9(64)$ & $15(71)$ & $6(30)$ & $5(56)$ & $42(49)$ \\
\hline
\end{tabular}

${ }^{\mathrm{a}} \mathrm{ECH}$, high $\geqq 1 \mathrm{ppm}$, low $<1 \mathrm{ppm} ; \mathrm{DMF}$, high $\geqq 10 \mathrm{ppm}$, low $<10 \mathrm{ppm}$

${ }^{\mathrm{b}}$ Smoking, smoking during 1 month before blood collection

${ }^{\mathrm{b}}$ Drinking, habitual alcohol drinking $\geqq$ once a week

$* P<0.05$, difference in exposure groups 


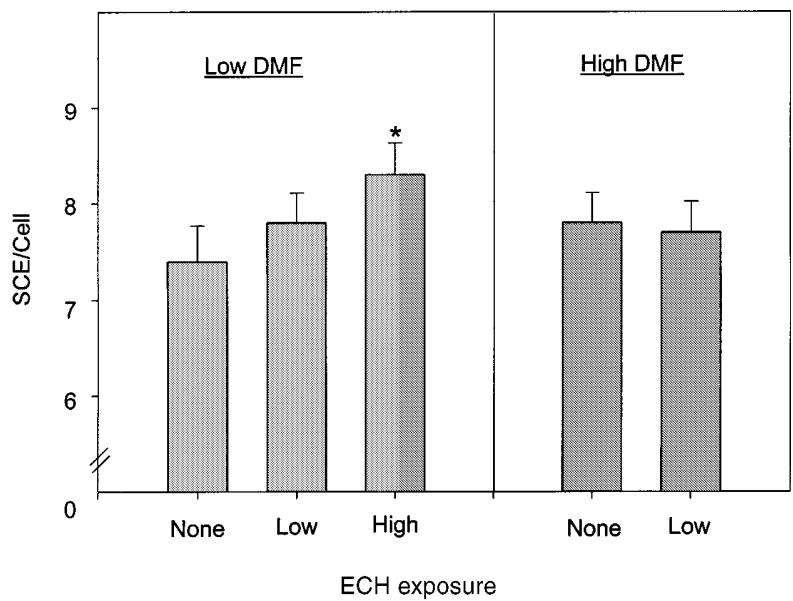

Fig. 1 SCE frequency by ECH and DMF exposure groups. Columns indicate mean SCE/cell; bars indicate SE. * Significantly different from the no-ECH exposure group, $P<0.05$. ( $S C E$ Sister chromatid exchange $\cdot E C H$ epichlorohydrin $\cdot D M F$ dimethylformamide)

previous studies have also shown that smoking can cause an increased SCE frequency (Dewdney et al. 1986; Husum et al. 1986; Bender et al. 1988; Cheng et al. 1995). Other authors have reported that the SCE frequency increases with age (Sarto et al. 1985; Husum et al. 1986). We did not find such an association in this study, possibly because of the small range of age distribution.

Workers with mean ECH exposure levels of approximately $0.1-0.2 \mathrm{ppm}$ did not have higher SCE frequency than those without ECH exposure, whereas workers with $\mathrm{ECH}$ exposure levels between 1 and 4 ppm had higher SCE frequencies than those without ECH exposure. Our findings are consistent with previous work on the chromosomal aberrations in $\mathrm{ECH}$ exposed workers (Sram et al. 1980, 1983; Webster et al. 1985). Epoxide compounds are reactive in nature and tend to form covalent bonds with macromolecules, including DNA; SCE presumably results from DNA adducts (Wiencke et al. 1990). Epoxides and other alkylating agents are potent SCE-inducing compounds (Wolff 1982). Thus, ECH may present genotoxicity through DNA adduct formation as well as through clastogenic effects.

Evidence for mutagenicity of DMF is limited. One recent study reported that DMF workers had increased SCE frequencies (Seiji et al. 1992). However, with a comprehensive design, we did not find an association of DMF exposure with SCE frequency. Because SCE assay is useful in assessing S-phase dependent genetic damage, the genotoxicity of DMF needs to be further assessed by other assays. Lack of mutagenic activity of dimethylformamide has been shown by bacterial mutation assay, in vitro observations of chromosomal aberration and sister chromatid exchange in human lymphocyte, and micronuclei in mouse bone marrow (Antoine et al. 1983; Mortelmans et al. 1986). A review on DMF genotoxicity by the World Health Organization also indicates DMF does not induce genetic damage in the in vivo and in vitro test system (WHO 1991).

Interestingly, workers with at least one GST M1 allele had lower SCE frequencies than those without a GST M1 allele. However, among smokers, the SCE frequency was not significantly different between individuals with GST M1-positive and GST M1-null geno-
Table 3 Sister chromatid exchange (SCE) frequencies by smoking, age, duration of employment, exposure categories, and genotypes

\begin{tabular}{|c|c|c|c|c|c|c|}
\hline \multirow[t]{3}{*}{ Variables } & \multicolumn{6}{|c|}{ SCE frequency } \\
\hline & \multicolumn{2}{|c|}{ Nonsmokers } & \multicolumn{2}{|c|}{ Smokers } & \multicolumn{2}{|l|}{ All } \\
\hline & $n$ & Mean \pm SD & $n$ & Mean \pm SD & $n$ & Mean $\pm \mathrm{SD}$ \\
\hline All & 43 & $7.3 \pm 1.1$ & 42 & $8.5 \pm 1.2^{*}$ & 85 & $7.9 \pm 1.3$ \\
\hline \multicolumn{7}{|l|}{ Age (years) } \\
\hline$\leqq 32$ & 28 & $7.5 \pm 0.9$ & 26 & $8.7 \pm 1.0$ & 54 & $8.1 \pm 1.1$ \\
\hline$>32$ & 15 & $6.8 \pm 1.3$ & 16 & $8.0 \pm 1.3$ & 31 & $7.5 \pm 1.4$ \\
\hline \multicolumn{7}{|c|}{ Duration of employment } \\
\hline$\leqq 5$ & 24 & $7.6 \pm 1.0$ & 25 & $8.5 \pm 1.2$ & 49 & $8.1 \pm 1.1$ \\
\hline$\overline{6}-10$ & 8 & $7.2 \pm 0.8$ & 14 & $8.4 \pm 1.3$ & 22 & $8.0 \pm 1.3$ \\
\hline$>10$ & 11 & $6.7 \pm 1.4$ & 3 & $8.1 \pm 0.7$ & 14 & $7.0 \pm 1.4$ \\
\hline \multicolumn{7}{|c|}{ ECH exposure } \\
\hline High ECH & 12 & $7.6 \pm 0.9$ & 9 & $9.3 \pm 1.6^{* *}$ & 21 & $8.3 \pm 1.5$ \\
\hline Low ECH & 16 & $7.1 \pm 1.1$ & 19 & $8.3 \pm 0.8$ & 35 & $7.7 \pm 1.1$ \\
\hline No ECH & 15 & $7.2 \pm 1.3$ & 14 & $8.1 \pm 1.1$ & 29 & $7.7 \pm 1.3$ \\
\hline \multicolumn{7}{|c|}{ DMF exposure } \\
\hline High DMF & 17 & $7.1 \pm 1.2$ & 17 & $8.5 \pm 1.0$ & 34 & $7.8 \pm 1.3$ \\
\hline Low DMF & 26 & $7.4 \pm 1.0$ & 25 & $8.5 \pm 1.3$ & 51 & $7.9 \pm 1.3$ \\
\hline \multicolumn{7}{|l|}{ GST M1 } \\
\hline Non-null & 18 & $7.1 \pm 1.0$ & 21 & $8.2 \pm 1.1$ & 39 & $7.7 \pm 1.2$ \\
\hline Null & 25 & $7.4 \pm 1.2$ & 21 & $8.7 \pm 1.2$ & 46 & $8.0 \pm 1.3$ \\
\hline \multicolumn{7}{|l|}{ GST T1 } \\
\hline Non-null & 19 & $7.3 \pm 1.2$ & 23 & $8.4 \pm 1.2$ & 42 & $7.9 \pm 1.3$ \\
\hline Null & 24 & $7.3 \pm 1.0$ & 19 & $8.6 \pm 1.2$ & 43 & $7.9 \pm 1.3$ \\
\hline
\end{tabular}

$* P<0.01$, smoking no vs yes; $* * P<0.02$, high $\mathrm{ECH}$ vs no $\mathrm{ECH}$, high ECH vs Low ECH 
Table 4 Multiple regression model for SCE

\begin{tabular}{lllc}
\hline & $\begin{array}{l}\text { Regression } \\
\text { coefficient }(\beta)\end{array}$ & $\begin{array}{l}\text { Standard } \\
\text { error }\end{array}$ & $P$ \\
\hline $\begin{array}{l}\text { Intercept } \\
\text { Age }\end{array}$ & 7.7 & 0.84 & $<0.01$ \\
$\begin{array}{l}\text { Smoking } \\
\quad \text { Yes vs no }\end{array}$ & -0.036 & 0.025 & 0.15 \\
$\begin{array}{l}\text { ECH } \\
\quad \text { High vs none }\end{array}$ & 0.3 & 0.24 & $<0.01$ \\
$\quad \begin{array}{l}\text { Low vs none } \\
\text { DMF }\end{array}$ & 0.05 & 0.37 & 0.01 \\
$\quad$ High vs low & 0.34 & 0.29 & 0.8 \\
$\quad$ NSTM1 & 0.46 & 0.30 & 0.26 \\
$\quad$ & & 0.24 & 0.06 \\
\hline
\end{tabular}

types. The role of smoking on the association of SCE frequency and GST genotypes requires further study. Similarly, GST M1 did not appear to influence the SCE frequency in $\mathrm{ECH}$-exposed workers, indicating that the effects of this agent not be modulated by GST M1. Again, the role of ECH on the association of SCE frequency with GST M1 genotypes needs further investigation.

In contrast, GST T1 genotypes were not associated with SCE frequency. Many chemicals have been found to be substrates for GST T1, including ethylene oxide, dihaloalkane and diepoxybutane (Fost et al. 1991; Their et al. 1991; Wiencke et al. 1995). It is not clear of ECH is metabolized by GST T1. A previous study reported that GST T1 might be largely responsible for variations in SCE frequency (Schroder et al. 1995; Wiencke et al. 1995). We did not find similar results in this study. Differences in ethnic backgrounds and in types of chemical exposure may be responsible for the discrepancy.

The mutagenicity of ECH was found to be absent or lower when mouse liver $\mathrm{S}_{9}$ mix was added to the Schizosaccharomyces pombe culture (Rossi et al. 1983a). Further study suggests that ECH may be metabolized by epoxide hydrase $(\mathrm{EH})$ to become inactive (Rossi et al. 1983b). Thus, more studies with EH may shed some light on the mechanism of ECH genotoxicity. In conclusion, ECH exposure may cause genotoxicity at a level $<5$ ppm, whereas DMF does not appear to be genotoxic.

Acknowledgements This study was supported by grants NSC 86-2621-B-002-010 and NSC 87-2621-B-002-010 from the National Science Council, Taiwan.

\section{References}

Antoine JL, Arany J, Leonard A, Henrotte J, Jenar-Dubuisson G, Decat G (1983) Lack of mutagenic activity of dimethylformamide. Toxicology 26: 207-212

Bender MA, Preston RJ, Leonard RC, Pyatt BE, Gooch PC, Shelby MD (1988) Chormosomal aberration and sister-chromatid exchange frequencies in peripheral blood lymphocytes of large human population samples. Mutat Res 204: 421-433
Bernardini S, Hirvonen A, Pelin D, Norppa H (1998) Induction of sister chromatid exchange by 1,2-epoxy-3-butene in cultured human lymphocytes: influence of GST T1 genotype. Carcinogenesis 19: 377-380

Cheng TJ, Christiani DC, Xu X, Wain JC, Wiencke JK, Kelsey KT (1995) GST mu, diet and smoking as determinants of sister chromatid exchanges in lymphocytes. Cancer Epidemiol Biomarkers Prev 4: 535-542

Comstock KE, Sanderson BJS, Claflin G, Henner WD (1990) GST1 gene deletion determined by polymerase chain reaction. Nucleic Acids Res 18: 3670

De Rooij BM, Commandeur JM, Ramcharan JR, Schuilenburg HP, Van Baar BM, Vermeulen NE (1996) Identification and quantitative determination of 3-chloro-2-hydroxypropylmercapturic acid and $\alpha$-chlorohydrin in urine of rats treated with epichlorohydrin. J Chromatogr B 685: 241-250

Dewdney RS, Lovell DP, Jenkinson PC, Anderson D (1986) Variation in sister-chromatid exchange among 106 members of the general UK population. Mutat Res 171: 43-51

Fleming LE, Shalat SL, Redlich CA (1990) Liver injury in workers exposed to dimethylformamide. Scand J Work Environ Health 16: 289-292

Fost U, Hallier E, Ottenwalder H, Bolt HM, Peter H (1991) Distribution of ethylene oxide in human blood and its implications for biomonitoring. Hum Exp Toxicol 10: 25-31

Husum B, Wulf HC, Niebuhr E (1986) Sister chromatid exchange frequency correlates with age, sex and cigarette smoking in a 5-year material of 553 healthy adults. Hereditas 105: 17-21

IARC monograph on the evaluation of the carcinogenetic risk of chemicals to humans (1982) Suppl 4. International Agency for Research on Cancer, Lyon, pp 122-124

Ketterer B (1988) Protective role of glutathione and glutathione transferase in mutagenesis and carcinogenesis. Mutat Res 202: 343-361

Konishi Y, Kawabata A, Denda A, Iketa T, Katada H, Maruyama $\mathrm{H}$ (1980) Forestomach tumors induced by orally administered epichlorohydrin in male Wistar rats. Gann 71: 922-923

Laskin S, Sellakumar AR, Kuschner M, Neson N, LA Mendola S, Rusch GM, Katz GV, Dulak NC, Aebert RE (1980) Inhalation carcinogenicity of epichlorohydrin in noninbred Spaque-Dawley rats. J Natl Cancer Inst 65: 751-757

Mortelmans K, Haworth S, Lawlor T, Speck W, Tainer B, Zeiger E (1986) Salmonella mutagenicity tests: II, Results from testing 270 chemicals. Environ Mutagen 8 (Suppl 7): 1-119

Nelson HH, Wiencke JK, Christiani DC, Cheng TJ, Zuo ZF, Schwartz BS, Lee BK, Spitz MR, Wang M, Xu XP, Kelsey KT (1995) Ethnic differences in the prevalence of the homozygous deleted genotype of glutathione S-transferase theta. Carcinogenesis 16: 1243-1245

Pemble S, Schroeder KR, Spencer SR, Meyer DJ, Hallier E, Bolt HM, Ketterer B, Taylor JB (1994) Human glutathione S-transferase theta (GSTT1): cDNA cloning and the characterization of a genetic polymorphism. Biochem J 300: 271276

Perry P, Wolff S (1974) New Giemsa method for the differential staining of sister chromatids. Nature 251: 156-158

Rossi AM, Migliore L, Barale R, Loprieno N (1983a) In vivo and in vitro mutagenicity studies of a possible carcinogen, trichloroethylene, and its two stabilizers, epichlorohydrin and 1,2-epoxybutane. Teratogen Carcinogen Mutagen 3: 75-87

Rossi AM, Migliore L, Loprieno N, Romano M, Salmona M (1983b) Evaluation of epichlorohydrin (ECH) genotoxicity. Microsomal epoxide hydrolase-dependent deactivation of ECH mutagenicity in Schizosaccharomyces pombe in vitro. Mutat Res 109: 41-52

Sarto F, Faccioli MC, Cominato I, Levis AG (1985) Aging and smoking increase the frequency of sister-chromatid exchanges (SCE) in man. Mutat Res 144: 183-187

Schroder KR, Wiebel FA, Reich S, Dannappel D, Bolt HM, Hallier E (1995) Glutathione-S-transferase (GST) theta polymorphism influences background SCE rate. Arch Toxicol 69: 505-507 
Seiji K, Inoue O, Cai S-X, Kawai T, Watanabe T, Ikeda M (1992) Increase in sister chromatid exchange rates in association with occupational exposure to N,N-dimethylformamide. Int Arch Occup Environ Health 64: 65-67

Sram RJ, Zudiva Z, Kuleshove NP (1980) Cytogenetic analysis of peripheral lymphocytes in worker exposed to epichlorohydrin. Mutat Res 70: 115-120

Sram RJ, Landa L, Samkova I (1983) Effect of occupational exposure to epichlorohydrin on the frequency of chromosomal aberration in peripheral lymphocytes. Mutat Res 122: $59-64$

Their R, Foest U, Deutschmann S, Schroeder KR, Hallier E, Peter H (1991) Distribution of methylene chloride in human blood. Arch Toxicol 14: 254-258

Van Poppel G, Verhagen H, Van Veer P, Van Bladeren PJ (1993) Markers for cytogenetic damage in smokers: association with plasma antioxidants and glutathione S-transferase $\mu$. Cancer Epidemiol Biomarkers Prev 2: 441-447

Wang JD, Lai MY, Chen JS, Lin JM, Chiang JR, Shiau SJ, Chang WS (1991) Dimethylformamide induced liver damage among synthetic leather workers. Arch Environ Health 46: $161-166$

Webster PW, Van der Heijden CA, Bisschop A, Van Essh GJ (1985) Carcinogenicity study with epichlorohydrin by gavage in rats. Toxicology 36: 325-339

White AD (1980) In vitro induction of SCE human lymphocytes by epichlorohydrin with and without metabolic activation. Mutat Res 78: 171-176

Wiencke JK, McDowell ML, Bodell WJ (1990) Molecular dosimetry of DNA adducts and sister chromatid exchanges in human lymphocytes treated with benzo[a]pyrene. Carcinogenesis 11: 1497-1502

Wiencke JK, Pemble S, Ketterer B, Kelsey KT (1995) Gene deletion of glutathione S-transferase theta: correlation with induced genetic damage and potential role in mutagenesis. Cancer Epidemiol Biomarkers Prev 4: 253-259

Wolff S (1982) Sister chromatid exchange. John Wiley \& Sons, New York

WHO (1991) Environmental Health Criteria 114: Dimethylformamide. World Health Organization, Geneva, pp 79-83 